\title{
Regimes \\ Internacionais e o \\ Contencioso das \\ Patentes para \\ Medicamentos: \\ Estratégias para \\ Países em \\ Desenvolvimento*
}

Gabriel Cepaluni**

\section{Introdução}

As relações internacionais são uma das últimas disciplinas das ciências sociais a se constituir como um campo "autônomo" do conhecimento. A primeira cátedra de relações internacionais foi fundada na Universidade de Wales (Aberystwyth), em 1919, sendo seguida pela London School of Economics and Political Science, em 1923, e pela Universidade de Oxford, em 1930.

Por ser uma disciplina nova, poucos livros e autores podem ser chamados de clássicos ou definitivos. Segundo Rosenberg (1994) - inspirado pelas críticas de Mills (1969) à sociologia norte-americana das décadas de 1940 e 1950 -, ainda não existe uma teoria das rela-

\footnotetext{
* Artigo recebido em setembro de 2004 e aceito para publicação em abril de 2005.

** Pesquisador do Centro de Estudos de Cultura Contemporânea (Cedec) e professor da Universidade do Vale do Itajaí (Univali).
} 
ções internacionais que entenda o mundo social como "totalidade"; somente "teorias parcimoniosas" preocupadas em resolver problemas específicos.

De acordo com Aron (1985:318), (1) "uma teoria (conhecimento contemplativo, percepção de idéias ou da ordem essencial do mundo) pode ser o equivalente de uma filosofia"; ou $\left(2^{\circ}\right)$ "uma teoria é um sistema hipotético-dedutivo constituído por um conjunto de proposições com termos definidos rigorosamente, cujas relações recíprocas (ou variáveis) se revestem quase sempre de forma matemática". Como veremos adiante, Rosenberg (1994) e Strange (1983) acreditam que as relações internacionais devem construir teorias do primeiro tipo, enquanto Waltz (1979) elabora uma teoria próxima do segundo significado.

O realismo-estrutural de Waltz $(1979 ; 2000)$ é um exemplo de uma "teoria parcimoniosa". O principal objetivo desse autor é explicar o papel dos Estados no sistema internacional, construindo um modelo formalizado a partir do realismo "clássico". No futuro, ele acredita que alguém unirá diversas "teorias parcimoniosas", construindo uma "teoria geral" que explique todos os elementos das relações internacionais de forma universal e atemporal. Por esse motivo, Waltz (1979; 2000) deixa de lado uma série de problemas e questões, pois não pretende analisar o mundo social em sua "totalidade".

As críticas formuladas por Mills (1969) e por Rosenberg (1994), em contextos mais gerais, encontram paralelo na seguinte afirmação de Strange (1983:351) a respeito dos estudos sobre instituições ou regimes internacionais ${ }^{2}$ :

"Persiste o pressuposto de que existe um Eldorado das ciências sociais, uma teoria geral aplicável universalmente a todos os tempos, lugares e questões [...]. Se (como muitos livros de relações internacionais concluíram) necessitamos de melhores 'ferramentas para análise', não é porque seremos capazes de extrair pedras preciosas com esses instrumentos. Essas pedras preci- 
Regimes Internacionais e o Contencioso das

Patentes para Medicamentos...

osas - as grandes verdades sobre a sociedade e a aventura humana - foram descobertas há muito tempo".

No entanto, a crítica de Strange (idem) parece ser mais direcionada a Waltz $(1979 ; 2000)$ - um dos teóricos mais importantes do realismo-estrutural ou do estruturalismo "convencional" - do que à literatura sobre regimes.

A teoria de Waltz dá pouca importância para vários temas e questões das relações internacionais, como, por exemplo, o papel dos regimes internacionais. Além disso, em suas análises, o autor preocupa-se principalmente com instituições de segurança militar, como fica claro no exemplo abaixo:

"Uma das críticas à teoria realista é que ela subestima a importância das instituições. A acusação é justa e o estranho fato de a OTAN (Organização do Tratado do Atlântico Norte) sobreviver aos seus propósitos mostra por que os realistas acreditam que as instituições internacionais são moldadas e limitadas por seus Estados fundadores [...]" (Waltz, 2000:18).

Segundo minha concepção, ainda não surgiu uma "teoria geral" das relações internacionais e os estudos sobre regimes também não atendem a essa demanda, o que não é necessariamente negativo, pois, em geral, esses estudos não buscam uma "verdade universal", apenas oferecem uma série de reflexões e perspectivas ${ }^{3}$. Conforme Ayoob (2002:28),

"[...] uma perspectiva não exclui outras perspectivas, pois, diferentemente da 'teoria', ela não almeja ser um repositório da 'verdade'. Uma 'perspectiva' se desenvolve a partir de insights anteriores, modificando e adaptando antigas perspectivas a situações contemporâneas. Ela é historicamente moldada e não deseja ser universal e atemporal".

Os institucionalistas admitem não existir uma teoria consolidada sobre os regimes internacionais. Estes são um fato social e as teorias institucionalistas são tentativas de ampliar a compreensão a seu respeito. Portanto, não existe uma única "teoria" sobre os regimes internacionais, mas um conjunto de estudos empíricos e teóricos. 
Após essas considerações, analisarei a noção de regime internacional de Mearsheimer (2000) e a de Krasner (1983a). Posteriormente, discutirei algumas abordagens sobre as instituições internacionais, segundo as tipologias de Krasner (idem) e de Hasenclever et alii $(1997)^{4}$. Finalmente, examinarei o contencioso das patentes entre o Brasil e os Estados, de meados da década de 1980 até 2001, utilizando alguns insights provenientes dos estudos sobre regimes.

\section{O Que São Regimes Internacionais?}

As ciências sociais necessitam de conceitos bem delimitados, pois a pluralidade terminológica impede a manutenção de um debate "científico" construtivo, prejudicando a comunicação entre os pesquisadores (Merton, 1968). Assim, examinarei dois significados para o conceito de regime internacional. Primeiramente, analisarei uma definição típica do realismo (Mearsheimer, 2000) e, depois, mostrarei por que a definição de Krasner (1983a) é mais interessante para a minha análise.

De acordo com Mearsheimer (2000:333), as instituições (ou regimes internacionais) são um conjunto de regras que estipulam "as formas como os Estados deveriam cooperar e competir entre si. Essas instituições prescrevem comportamentos estatais aceitáveis e proscrevem tipos inaceitáveis de comportamento".

Para esse autor (idem), as regras são parte da estrutura jurídica das instituições internacionais, porém os regimes não "forçam" os Estados a obedecerem-nas. As instituições não são uma forma de governo mundial; os Estados escolhem se respeitam ou não as regras criadas por eles próprios. Em outras palavras, as instituições requerem uma cooperação descentralizada de unidades soberanas (Estados), sem qualquer mecanismo efetivo de comando superior ao poder estatal. 
Regimes Internacionais e o Contencioso das

Patentes para Medicamentos...

Uma crítica a Mearsheimer é que ele desconsidera a emergência dos "novos atores" - Organizações Não Governamentais (ONGs), multinacionais etc. - que vêm aumentando sua capacidade de influência na formulação das políticas praticadas pelos Estados (que ainda são o locus privilegiado do poder internacional ${ }^{5}$ ), assim como também ganham crescente espaço em regimes internacionais. Por tal motivo, uma maior flexibilização do modelo realista parece necessária. Esta é a proposta de Keohane e Nye (1989).

O modelo teórico destes autores, batizado de "interdependência complexa”, tenta explicar a dinâmica das políticas mundiais após a Guerra Fria e ajuda a compreender as relações entre os Estados e os atores "transnacionais", sendo uma alternativa ao realismo-estrutural.

O conceito de "interdependência" refere-se a situações em que os atores se afetam mutuamente. De forma simplificada, interdependência significa dependência mútua. Todo processo de interdependência apresenta pelo menos um dos quatro elementos a seguir: os recursos, os benefícios, os custos relativos e a simetria.

Os recursos da interdependência geralmente estão relacionados aos aspectos geográficos (tamanho do território, da população, capacidade agrícola etc.) e sociais (econômicos e políticos) de um país. Nas políticas internacionais, o comportamento estatal reflete a percepção que se tem dos outros Estados. Não basta ter recursos de poder reais, mas também simbólicos. Em outras palavras, a crença no poder de um país pode "valer" tanto quanto suas verdadeiras capacidades ${ }^{6}$.

Os benefícios da interdependência são expressos como um jogo de soma zero ou de soma diferente de zero. Em uma situação de soma zero, a perda de um é equivalente ao ganho de outro. Em uma situação de soma positiva, ambos ganham; em uma situação de soma negativa, ambos perdem. 
Os custos da interdependência envolvem os conceitos de sensibilidade e de vulnerabilidade. A sensibilidade refere-se à rapidez e à intensidade dos efeitos da dependência, ou seja, mede em quanto tempo uma alteração em uma parte do sistema internacional provoca uma mudança em outra parte. A vulnerabilidade refere-se aos custos relativos provocados pela alteração da estrutura de um sistema interdependente e pode ser definida como a suscetibilidade de um ator sofrer os custos impostos por eventos externos (Keohane e Nye, 1989; Nye Jr., 1997). Como veremos adiante, o contencioso com os Estados Unidos em torno das patentes farmacêuticas foi uma questão sensível para o Brasil, pois a não-aceitação das posições mais rígidas com relação à propriedade intelectual resultou em uma retaliação ${ }^{7}$ unilateral norte-americana contra o país, em 1988. Por outro lado, o Brasil não era totalmente vulnerável às pressões dos Estados Unidos, pois somente alterou seu código de propriedade intelectual em 1996, suportando os "custos" impostos pela sanção norte-americana.

Por último, a simetria refere-se a uma situação de relativo equilíbrio e a assimetria diz respeito a uma situação de dependência desigual. A simetria perfeita é bastante rara; contudo, existem casos de completo desequilíbrio, em que um dos lados é totalmente dependente.

Pode-se estabelecer uma relação entre os processos de interdependência e os regimes internacionais, pois, ao elaborar e definir agendas políticas, os Estados criam instituições para resolver conflitos provocados por situações de interdependência. Esses Estados tentam usar os regimes internacionais para maximizarem seus ganhos ou minimizarem suas perdas.

O modelo de "interdependência complexa" pode ser entendido como um "tipo ideal"; contudo, os autores "interdependentistas" acreditam que este modelo é mais condizente com a realidade do mundo pós-Guerra Fria do que a perspectiva realista (Keohane e Nye, 1989; 1998; Nye Jr., 1997). 
Regimes Internacionais e o Contencioso das

Patentes para Medicamentos...

A "interdependência complexa" questiona algumas premissas do realismo. Em primeiro lugar, os Estados não são os únicos atores importantes, os atores "transnacionais" também são relevantes no cenário internacional. Em segundo, a força militar não é o único instrumento das políticas mundiais; existem outros, como as sanções econômicas e as instituições internacionais. Finalmente, os realistas assumem que a força militar é a principal meta das políticas mundiais. No entanto, a capacidade bélica pode ser irrelevante para resolver desacordos em questões econômicas mediadas por um regime internacional (Keohane e Nye, 1989; 1998; Nye Jr., 1997).

Outra contribuição desses autores consiste na "redefinição" do sentido da palavra "poder". Conforme Keohane e Nye (1998), é possível a distinção entre hard power (a posse de recursos para alcançar resultados almejados e soft power (a habilidade de obter os resultados desejados).

O hard power é a capacidade de alcançar certos objetivos por meio do uso efetivo ou potencial da força, sendo parecido com a noção realista "clássica" de poder. Segundo Weber (1991:33), poder é "toda probabilidade de impor a própria vontade em uma relação social, mesmo contra resistências". Como escreve Aron (1979:79, ênfase no original), "no campo das relações internacionais, poder é a capacidade que tem uma unidade política de impor sua vontade às demais".

O soft power não reside na possibilidade do uso da força militar nem nos incentivos e sanções econômicas; ele insere-se na noção de "poder comportamental" e fundamenta-se nas ideologias e nos aspectos culturais manifestados pelos Estados ou por outros atores "transnacionais". Na política mundial, é possível que um país obtenha os resultados que quer porque os outros desejam acompanhá-lo, admirando seus valores, imitando-lhe o exemplo. O soft power não é sinônimo de influência; afinal, pode-se influenciar com ameaças e recompensas. É mais do que persuasão ou capacidade de mover as pessoas pela 
argumentação. É a capacidade de seduzir e atrair, geralmente, levando-se à imitação. Ele emana em grande parte dos valores que se expressam na cultura, na política doméstica e no comportamento internacional dos países (Keohane e Nye, 1989; Nye Jr., 2002).

"O soft power [...] é a habilidade para conseguir resultados desejados porque os outros querem o que você quer. É uma habilidade para atingir metas por meio da atração em vez da coerção. [...] O soft power reside no apelo às idéias, à cultura ou à habilidade para organizar agendas por meio de padrões ou instituições que moldam a preferência dos outros atores" (Keohane e Nye, 1998:4).

O debate iniciado pelo livro Power and Interdependence (Keohane e Nye, 1989) é fundamental para o entendimento do papel dos "novos atores". O aumento do número e o crescimento da importância das ONGs e das empresas multinacionais tornam imprescindível a inclusão desses atores em um modelo teórico consistente. Além do mais, como enfatizei, os regimes internacionais são criados para intermediar conflitos que ocorrem em um contexto de interdependência, idéia esta também compartilhada por Haas (1983:26-27):

"Os regimes são acordos feitos pelos homens (são instituições sociais) para gerenciar conflitos em um quadro de interdependência, pois, como Oran Young disse: 'o crescimento da interdependência aumenta a capacidade de todos os atores relevantes se ferirem mutuamente'. A interdependência implica uma rede não-fortuita entre os atores, estabelecendo ligações organizadas e estruturadas".

Assim, os regimes internacionais apenas são possíveis em um contexto de interdependência, pois os Estados (e os atores "transnacionais") estabelecem acordos para mediar conflitos somente quando são mutuamente dependentes. Segundo meu ponto de vista, a interdependência é uma característica permanente do sistema internacional, pois, a partir do momento que dois países se relacionam (por meio do comércio, da guerra etc.), existe uma relação de dependência mútua. Portanto, uma noção atualizada de regime internacional 
Regimes Internacionais e o Contencioso das

Patentes para Medicamentos...

deve incorporar o conceito de atores "transnacionais" e, acima de tudo, valorizar a idéia de interdependência.

A noção de Krasner (1983a) fornece uma definição de regime internacional que contempla o papel dos atores "transnacionais"; considera os regimes como "princípios, normas, regras e procedimentos implícitos e explícitos"; e deixa claro que os regimes tratam de uma área específica das relações internacionais:

"Os regimes são definidos como um conjunto de princípios, normas, regras e procedimentos de tomada de decisão, implícitos ou explícitos, ao redor dos quais as expectativas dos atores convergem em uma dada área das relações internacionais. Os princípios são crenças sobre fatos, causalidades e retitude. As normas são padrões de comportamento definidos em termos de direitos e de obrigações. As regras são prescrições ou proscrições específicas para a ação. Os procedimentos de tomada de decisão são práticas para formular e implementar a ação coletiva" (idem:2).

Diferentemente da noção de Mearsheimer (2000), esse conceito incorpora os atores "transnacionais" como elementos da análise, pois Krasner (1983a) utiliza a palavra "atores" (actors) e não Estados Nacionais.

De acordo com o meu entendimento da noção de Krasner, os regimes não abrem espaço somente para a participação dos Estados Nacionais. Muitos deles, como a Organização Mundial de Comércio (OMC), somente aceitam Estados como membros efetivos. Por outro lado, os atores "transnacionais" (principalmente as empresas multinacionais, mas também as ONGs) influenciam na elaboração da agenda dessas instituições internacionais e também ajudam a criar ou a alterar "princípios, normas, regras e procedimentos implícitos e explícitos" (Sanchez, 2002; 2004). Dessa forma, mesmo que os atores "transnacionais" não sejam membros efetivos de um regime internacional, eles participam do processo de criação e de mudança dos "princípios, normas, regras e procedimentos implícitos e explícitos" presentes em determinada instituição internacional. 


\section{Tipologia das Escolas de Regimes}

Segundo Krasner (1983a), existem três escolas de pensamento que estudam os regimes internacionais: os grocianos ${ }^{8}$, os estruturalistas "convencionais" e os estruturalistas "modificados".

Os grocianos vêem os regimes como uma característica permanente do sistema internacional, no qual nenhum modelo comportamental pode sustentar a si mesmo por muito tempo sem criar um regime. Para a escola grociana, os regimes e os comportamentos estão inexoravelmente interligados:

"Essa perspectiva sobre regimes enfatiza que eles são um artefato humano, não tendo existência ou significado à parte do comportamento dos indivíduos ou de grupos de seres humanos. [...] Nota-se que os regimes internacionais, como outras instituições sociais, geralmente são produtos do comportamento de um grande número de indivíduos ou grupos. Embora os regimes reflitam o comportamento de seus participantes, os atores individuais geralmente não são capazes de influenciar isoladamente as características de um regime" (Young, 1983:95-96).

Os estruturalistas "convencionais" entendem que a noção de regime internacional é um conceito que obscurece as relações econômicas e de poder, pois eles não acreditam que as instituições sejam importantes, ou seja, deixam em segundo plano (ou rejeitam) os aspectos normativos do sistema internacional.

Finalmente, os estruturalistas "modificados" sustentam que em condições restritivas, em que os Estados são incapazes de obter o ótimo de Pareto ${ }^{9}$, os regimes internacionais podem ter um impacto significativo até mesmo na ordem anárquica ${ }^{10}$. Esses autores aceitam os pressupostos básicos do realismo-estrutural, que descreve um sistema internacional anárquico, no qual os Estados procuram maximizar seus interesses. Contudo, acreditam que os "princípios, normas, regras e procedimentos de tomada de decisão" têm um papel importan- 
Regimes Internacionais e o Contencioso das Patentes para Medicamentos...

te no cenário internacional. Os estruturalistas "modificados" acreditam que os Estados são atores racionais e que a cooperação internacional é necessária, em determinados momentos, para mediar possíveis conflitos.

"Procuramos entender por que atores auto-interessados buscam, em certas circunstâncias, criar regimes internacionais por meio de acordos mútuos e também como podemos analisar as oscilações ao longo do tempo no número, na extensão e na força dos regimes internacionais sob a base de um cálculo racional que se inscreve em um contexto em que a conjuntura é variável" (Keohane, 1983:141-142).

Hasenclever et alii (1997) fazem uma classificação semelhante à de Krasner (1983a). Porém, entendem que a abordagem estruturalista "convencional" é uma ramificação do realismo. Além disso, o sentido do termo estruturalismo "modificado" é semelhante ao que eles chamam de neoliberalismo, enquanto o sentido da palavra grociano se parece muito com a definição dada à escola cognitivista.

Para eles, existem três linhas teóricas ${ }^{11}$ (ou perspectivas) preocupadas com os estudos sobre os regimes: a realista (baseada nas relações de poder); a neoliberal (baseada no interesse); e a cognitivista (baseada no conhecimento). Na Tabela 1, Hasenclever et alii (1997:6) descrevem as principais características dessas escolas.

A perspectiva baseada no poder (realista) assume que os Estados não se importam somente com os ganhos absolutos (situação em que existe maximização dos benefícios), mas também com os ganhos relativos. Os ganhos (ou perdas) relativos aplicam-se a situações em que os Estados devem escolher se continuam cooperando com outros Estados ou se adotam medidas unilaterais. Em tais situações, as decisões dos Estados não dependerão apenas de seus desempenhos na cooperação, mas também do sucesso (pay-off) de seus parceiros (idem:116). Esse raciocínio é similar ao desenvolvido por Waltz (1979:105): 
Gabriel Cepaluni

\section{Tabela 1}

Perspectivas ou Abordagens sobre Regimes Internacionais

\begin{tabular}{c|c|c|c}
\hline Variável Central & Poder & Interesse & Conhecimento \\
\hline $\begin{array}{c}\text { Importância dada } \\
\text { às Instituições }\end{array}$ & Pouca & Média & Muita \\
\hline $\begin{array}{c}\text { Orientação } \\
\text { Metateórica }\end{array}$ & Racionalista & Racionalista & Sociológica \\
\hline $\begin{array}{c}\text { Modelo } \\
\text { Comportamental }\end{array}$ & $\begin{array}{c}\text { Preocupado } \\
\text { com os ganhos } \\
\text { relativos }\end{array}$ & Maximizador absolutos de & $\begin{array}{c}\text { Jogador que analisa as suas } \\
\text { possibilidades e o contexto } \\
\text { em que está jogando } \\
\text { (Role-Players) }\end{array}$ \\
\hline
\end{tabular}

Fonte: Adaptada de Hasenclever et alii (1997:6).

"Quando deparados com a possibilidade de uma cooperação com ganhos mútuos, os Estados que se sentem inseguros devem se perguntar como o ganho será dividido. Eles também serão compelidos a perguntar: 'os dois ganharão?', mas 'quem ganhará mais?'. Se se espera que o ganho será dividido, por exemplo, na razão de 2 para 1, um dos Estados pode utilizar o seu ganho desproporcional para implementar uma política para prejudicar ou destruir as outras nações. Até os grandes ganhos absolutos para ambas as partes não produzem cooperação por muito tempo, pois cada um teme como o outro utilizará suas crescentes capacidades. Nota-se que os impedimentos à colaboração podem não residir na intenção imediata dos Estados. Todavia, a condição da insegurança - a incerteza a respeito das ações e das intenções futuras dos outros - trabalha contra a cooperação".

De acordo com Hasenclever et alii (1997), alguns realistas atribuem um papel significativo às instituições internacionais e reconhecem que a cooperação interestatal (ocorrida por meio de regimes) é uma realidade que necessita ser explicada. Esses realistas argumentam que a distribuição de recursos de poder entre os atores afeta fortemente o surgimento de novos regimes. Outros realistas, ao enfatizarem que o diferencial de poder entre os Estados cria obstáculos para a 
Regimes Internacionais e o Contencioso das Patentes para Medicamentos...

cooperação internacional, tendem a questionar a importância dos regimes internacionais (Strange, 1983; Mearsheimer, 2000).

A perspectiva baseada no interesse (ou neoliberal) é a abordagem mainstream dos estudos sobre as instituições internacionais. Embora esses autores neoliberais não sejam insensíveis às diferenças de poder entre os Estados, eles enfatizam o papel dos regimes internacionais como instrumento para que os Estados busquem interesses em comum. Ao fazerem isso, retratam os Estados como atores racionais e egoístas, preocupados somente com seus respectivos ganhos absolutos. Os regimes permitem que os Estados Nacionais coordenem seus comportamentos para evitar resultados subótimos em situações cooperativas. Por esse motivo, os Estados somente têm interesse na manutenção de um regime enquanto os elementos que justificaram a sua criação forem considerados importantes (Hasenclever et alii, 1997).

A perspectiva cognitivista (baseada no conhecimento) pode ser classificada em dois subgrupos: o cognitivismo "fraco" e o "forte" ${ }^{\text {, }}$. Os estudos sobre regimes baseados no conhecimento criticam as abordagens neoliberais, argumentando que a noção de interesse não é dada exogenamente. Segundo os cognitivistas, nenhuma noção pode ser considerada como dada, pois elas merecem explícita elaboração conceitual. No entanto, os cognitivistas "fracos" entendem que as idéias são uma variável interveniente para explicar conceitos como interesse e poder; enquanto os "fortes" defendem uma interpretação relativista, em que "apenas as idéias importam e podem ser estudadas” (Adler, 1999:204). Conforme Adler (ibidem),

"[...] o dilema epistemológico e ontológico chave que foi levantado pelas abordagens relativistas é descrito como o 'círculo hermenêutico' - sempre que alguém tenta estabelecer uma certa leitura para um texto ou expressão, cita outras leituras como base para a sua. [...] O dado empírico [...] tornou-se apenas mais uma interpretação [...]". 
Os cognitivistas "fracos" valorizam o papel das idéias nos regimes internacionais, pois novos entendimentos do ambiente social e político (1) fazem com que os formuladores de decisão (decision makers) modifiquem seus planos para atingirem basicamente as mesmas metas; ou (2) fazem com que tais formuladores redefinam o interesse nacional de seus países, o que envolve novos objetivos e estratégias (Haas, 1990). Assim, as comunidades epistêmicas (redes de cientistas e de especialistas que compartilham idéias e se esforçam para influenciar políticas) e outros atores "transnacionais" (como ONGs e empresas multinacionais) alteram o interesse dos Estados e os objetivos dos regimes internacionais (Keck e Sikkink, 1998; 1999). Parte da contribuição dessas teorias cognitivistas "fracas" pode ser vista como complementar ao mainstream racionalista-neoliberal (Keck e Sikkink, 1998; 1999; Adler, 1999; Hasenclever et alii, 1997), pois ajuda a explicar alguns conceitos não explicitados.

Talvez como reação às críticas, Nye Jr. (2002:228) - autor geralmente classificado como neoliberal - conceba uma definição de interesse baseada em idéias e valores:

“[...] em uma democracia, o interesse nacional é simplesmente aquilo que os cidadãos definem como tal após a devida deliberação. [...] Os valores são simplesmente um interesse nacional intangível. Se o povo americano achar que os nossos interesses compartilhados a longo prazo incluem certos valores e a sua promoção no exterior, estes passam a fazer parte do interesse nacional. As lideranças e os especialistas têm todo o direito de mostrar o custo de cultivar esses valores, mas se um público informado discordar, não podemos negar legitimidade a sua opinião".

Por outro lado, alguns cognitivistas acreditam que o institucionalismo "informado" pela perspectiva sociológica é mais apropriado do que o baseado na teoria da escolha racional. Conforme Cox (1986:208), uma "teoria" deve se situar externamente à ordem prevalecente no mundo e se perguntar como essa ordem surgiu. Tais cognitivistas "fortes" apontam que as abordagens baseadas nos interesses 
Regimes Internacionais e o Contencioso das

Patentes para Medicamentos...

fornecem uma fotografia truncada dos recursos de um regime robusto ${ }^{13}$, pois não levam em consideração as influências das instituições sobre as identidades dos atores internacionais (Hasenclever et alii, 1997). Contudo, por causa da diversidade das análises cognitivistas, há pouca clareza sobre sua natureza e conteúdo. Como aponta Adler (1999:202), "os debates internos sobre 'do que se trata o construtivismo", que se entende como uma expressão do cognitivismo, "[...] tendeu a obscurecer a base científica do construtivismo, sua preferência pela ontologia e pela epistemologia frente à metodologia, e sua contribuição potencial para um melhor entendimento das relações internacionais".

Segundo minha perspectiva, as tipologias elaboradas por Krasner (1983a) e por Hasenclever et alii (1997) só podem ser entendidas como "tipos ideais", ou seja, uma imagem caricata da "realidade" que abstrai dos fenômenos concretos as suas características mais marcantes (Weber, 1991; 1999).

Tais "tipos ideais" raramente são encontrados na realidade de forma "pura" e muitas vezes empobrecem o pensamento de autores que não se encaixam perfeitamente em certas correntes de pensamento. Contudo, as tipologias são necessárias para expor de forma simples e clara as semelhanças e as diferenças básicas entre as diversas perspectivas "teóricas" (ou fenômenos "histórico-concretos", segundo a linguagem weberiana).

Como havia apontado, as tipologias de Krasner (1983a) e de Hasenclever et alii (1997) apresentam muitos pontos em comum. Por isso, farei uma síntese das duas classificações e dividirei os estudiosos (ou críticos) de regimes em três grupos: os estruturalistas "convencionais", também chamados realistas ou realistas-estruturais; os estruturalistas "modificados" ou neoliberais; e os cognitivistas. 


\section{Regimes Internacionais e o Contencioso entre Brasil e Estados Unidos em Torno das Patentes para Medicamentos}

Nesta última seção, analisarei o contencioso entre o Brasil e os Estados Unidos em torno das patentes farmacêuticas, focalizando a participação desses países nas negociações relacionadas ao grupo de Acordo sobre Aspectos dos Direitos de Propriedade Intelectual Relacionados ao Comércio (TRIPS, na sigla em inglês). Para examinar o tema, utilizarei a noção de regime internacional de Krasner (1983a), privilegiando a perspectiva neoliberal ou estruturalista "modificada". Escolhi essa abordagem, pois acredito que ela responde melhor às minhas perguntas de pesquisa. Tenho consciência de que as perspectivas apresentadas (realismo, neoliberalismo e cognitivismo) são produzidas por meio de um permanente diálogo "metatéorico". Por isso, não descartarei eventuais insights provenientes de outras abordagens. Assim, a perspectiva neoliberal será um guia para estruturar minha análise, não "mandamentos" ou "leis" que condicionem as respostas de pesquisa.

Parto do pressuposto de que os Estados Unidos e o Brasil são os principais atores do conflito e ambos procuram maximizar seus respectivos interesses. Os atores estatais têm uma importância central neste estudo, pois acredito que os Estados são os principais atores do sistema internacional, assim como entendem diversos autores das mais variadas perspectivas (Wendt, 1994; 2004; Keohane e Nye, 1989; 1998; Krasner, 2001; Waltz, 1979). Por outro lado, estou ciente de que os atores "transnacionais" - por exemplo, as empresas multinacionais e as ONGs - ganham cada vez mais visibilidade e influência na agenda internacional ${ }^{14}$. Considero também que as negociações para a criação e a manutenção de regimes internacionais condicionam e são restritas pelas políticas internas dos Estados participantes 
Regimes Internacionais e o Contencioso das Patentes para Medicamentos...

dessas instituições ${ }^{15}$. Iniciarei analisando as pressões norte-americanas, na década de 1980, para que antigos parceiros comerciais (entre eles, o Brasil) adotassem padrões rígidos e uniformes de proteção à propriedade intelectual, e terminarei descrevendo os ganhos relativos dos países em desenvolvimento durante a IV Conferência Ministerial de Doha, em 2001.

Em meados da década de 1980, os Estados Unidos estavam bastante preocupados com seu relativo declínio econômico (Kennedy, 1989a; 1989b; Arrighi, 1994; Gilpin, 2002), o que incentivava o endurecimento da política externa norte-americana com relação aos seus antigos parceiros comerciais. Além disso, essa década foi marcada por transformações tecnológicas radicais e pela aceleração da globalização econômica, quando os Estados Unidos passaram a prestar mais atenção às pressões dos setores internos de alta tecnologia que buscavam medidas mais rígidas para a manutenção de seus interesses e para a expansão de suas atividades a terceiros mercados (Vaitsos, 1989). Nesse sentido, "[...] os bens imateriais se tornam cada vez mais importantes para a sobrevivência das indústrias, e para as estratégias que elas devem implementar nos âmbitos nacional e internacional” (Basso, 2000:160). Segundo Vigevani (1995:63-64), a política de comércio exterior norte-americana sofreu forte inflexão no segundo semestre de 1984:

"O debate sobre o declínio ou não da potência do país [...] acentuou-se já na segunda metade do primeiro mandato Reagan. Em face dos perigos emergentes, a tentativa - como hoje sabemos, fracassada - de reequilíbrio do orçamento e do déficit norte-americano acabou levando, ainda no segundo semestre de 1984, a uma forte inflexão, cujas conseqüências foram em parte amplificadas pelo momento de nova campanha eleitoral presidencial. Mas não se tratava de manobra de cunho imediatista".

Assim, o governo norte-americano recorre a políticas mais agressivas, buscando defender seus interesses econômicos. Com essa estratégia, intensifica o protecionismo comercial em áreas pouco compe- 
titivas, como o setor siderúrgico; ao mesmo tempo, defende a abertura e a regulamentação comercial em áreas onde os seus produtos encontravam menos concorrência, como era o caso da indústria farmacêutica.

Muitas vezes, as pressões norte-americanas contaram com o apoio da Comunidade Européia, mas certamente os Estados Unidos foram mais obstinados do que seus parceiros europeus na busca de seus interesses. Um exemplo dessa obstinação foi a retaliação unilateral contra o Brasil, em 1988, para forçar o país a adotar regras mais rígidas de proteção à propriedade intelectual.

As pressões do United States Trade Representative (USTR) e a percepção de que a liderança econômica dependia da defesa de setores de alta tecnologia favoreceram o endurecimento das negociações para criação de regimes internacionais e intensificaram ações bilaterais contra países que atrapalhavam os objetivos dos Estados Unidos. Muitas vezes, as pressões bilaterais norte-americanas também visavam metas multilaterais. Segundo Vigevani (idem:67):

“[...] a ênfase da administração Reagan no bilateralismo repousa na convicção de que os progressos graduais obtidos em arranjos contratuais sucessivos, firmados isoladamente com certos parceiros, serviriam para apressar a emergência de uma nova rodada de conversações multilaterais. A Rodada Uruguai do GATT [The General Agreement on Tariffs and Trade] demonstrou ser verdadeira esta interpretação, provando que os temas do bilateralismo necessitavam consolidar-se no órgão multilateral, apesar de todas as dificuldades".

Nesse contexto, é possível entender a posição norte-americana diante da questão dos direitos dos detentores de patentes, uma vez que os países em desenvolvimento eram alvos constantes da seção 301 do USTR (2002). Conforme Arslanian (1994:11),

“[...] as práticas comerciais supostamente distorcivas, atribuídas a potências comerciais, como Japão e CEE, tendem a não ser submetidas à ação da 301, ao menos no que se refere à sua aplicação posterior à Lei Abrangente de 
Regimes Internacionais e o Contencioso das

Patentes para Medicamentos...

1988. Por outro lado, aquelas práticas atribuídas a parceiros comerciais intermediários, de que são exemplos Brasil, Índia e Coréia, países economicamente mais expostos a demonstrações de força dos EUA, têm sido condenadas, com base na seção 301 [...]”.

Pode-se argumentar que as medidas pertencentes ao âmbito da seção 301 aplicadas contra os países em desenvolvimento também serviam como um aviso ao Japão (Dryden:1995). Conforme Evans (1990:325), os países-alvo da seção 301 não se tratavam "apenas de pecadores contra o regime de livre-comércio, mas de rivais bem-sucedidos, ou rivais em potencial, culpados da adoção de práticas neomercantilistas para melhorar sua posição na hierarquia das nações". A seção 301 do "Trade Act of 1974" determina que o USTR deve tomar providências se "um ato, política ou prática de um país estrangeiro for não-razoável ou discriminatório e prejudicar ou restringir o comércio dos Estados Unidos [...]"(United States, 1974:1.019). Essas ações não são somente reações a práticas comerciais consideradas ilegais, mas também "não razoáveis": "um ato, política ou prática é não razoável se [...], mesmo não violando os direitos internacionais dos Estados Unidos, for injusto e desigual" (idem:1.021).

No plano multilateral, a política externa norte-americana esforçava-se para incluir o tema dos direitos dos detentores de patentes no GATT, substituindo a liberdade nacional de aplicação de padrões de proteção prevista pela Convenção da União de Paris, de 1883, pela adoção de normas e de regras mais rígidas por todas as partes contratantes (Arslanian e Lyrio, 1995).

Como reação à proposta norte-americana, alguns países em desenvolvimento, especialmente a Índia e o Brasil, sugeriram que a discussão sobre a propriedade das patentes deveria ser de responsabilidade da Organização Mundial de Propriedade Intelectual (OMPI). No entanto, os Estados Unidos, com o apoio da Comunidade Européia, conseguiram não somente "transformar o GATT no principal fórum 
internacional para discussão e regulamentação do tema, mas também aprovar, a partir de 1990 [...] um texto final do grupo de TRIPS" que se aproximava "muito mais da world class protection que pregavam os norte-americanos" do que das propostas formuladas pelos países em desenvolvimento (idem).

Segundo Drahos (2003), quando o Quad (Quadrilateral), coalizão formada pelos Estados Unidos, União Européia, Japão e Canadá, chegou a um razoável consenso sobre como deveria ser a agenda do GATT/OMC, os países em desenvolvimento passaram a ter um espaço bem limitado nas negociações. A criação do Quad seguiu uma lógica relativamente comum nas negociações multilaterais lideradas pelos norte-americanos. Os Estados Unidos e o Canadá criaram um consenso sobre princípios amplos. Posteriormente, negociaram, respectivamente, com a União Européia e o Japão temas mais específicos. Assim, após os quatro países chegarem a um acordo, eles passaram a argumentar que as nações em desenvolvimento deveriam adotar padrões de propriedade intelectual semelhantes aos adotados pelo mundo desenvolvido (Braithwaite, 2004:17).

Uma das razões da debilidade das políticas de oposição formuladas pelos países em desenvolvimento decorre de eles não conseguirem levar adiante um projeto que sintetizasse o interesse de nações tão diferentes entre si. A oposição partiu de uma coalizão de países em desenvolvimento, na qual o Brasil e a Índia desempenharam um papel proeminente. Tal coalizão, conhecida como G- $10^{16}$, era composta de países com interesses diversificados. Segundo Abreu (2001:93), o posicionamento do G-10 baseava-se em argumentos totalmente divergentes,

"[...] que iam da resistência à inclusão, na agenda, de temas que vinham sendo tradicionalmente tratados por outras agências até as dúvidas em torno da falta de competência analítica e da experiência em negociação de semelhantes temas, bem como da natureza assimétrica das vantagens promovidas pela liberalização". 
Regimes Internacionais e o Contencioso das

Patentes para Medicamentos...

Em relação ao grupo de TRIPS, a posição indiana e de outros países em desenvolvimento, como a Argentina, começava a se distanciar gradativamente da proposta brasileira. Em 2001, segundo Abreu (idem:94), a posição do G-10 já dava sinais de falta de coesão, principalmente por causa da "[...] polarização das negociações sobre têxteis e TRIPS". Relativamente ao TRIPS, discutia-se se o tema de propriedade intelectual deveria ser negociado no GATT ou na OMPI, sendo que os países em desenvolvimento, especialmente o Brasil e a Índia, inicialmente resistiam à proposta norte-americana de inserir no GATT um regime internacional de propriedade intelectual. Contudo, "à medida que a oposição indiana diminuía, a postura dos países desenvolvidos ia prevalecendo [...]" (ibidem).

Shukla (2002) tem uma visão um pouco diferente a respeito da dificuldade de a Índia e o Brasil manterem suas posições. Segundo o autor, os dois países acabaram aceitando o alargamento do GATT, conforme a concepção norte-americana, pois os Estados Unidos estavam utilizando medidas unilaterais desde 1984. Primeiramente, em 1988, o governo norte-americano aplicou sanções contra o Brasil no caso das patentes farmacêuticas. Posteriormente, em maio de 1989, a Índia também foi objeto de retaliações. Além disso, a situação política interna dos dois países era preocupante, diminuindo a capacidade deles se posicionarem mais firmemente no plano internacional. Conseqüentemente, a parceria Índia-Brasil enfraqueceu-se, resultando em uma falta de coordenação e de consultas mútuas que deixou poucos rastros de confiança entre os dois países. Assim, a posição dos países em desenvolvimento debilitava-se, enquanto os países industrializados viam oportunidades de obter vantagens nas negociações (idem:265). Sell e Prakash (2004:159) concordam que o enfraquecimento da posição dos países em desenvolvimento foi decorrente das pressões do USTR:

"Em abril de 1989, os países em desenvolvimento finalmente aceitaram a inclusão de um código de propriedade intelectual no GATT. Eles esperavam 
que as pressões da seção 301 diminuíssem com essa decisão. Inicialmente, as nações em desenvolvimento viam uma opção entre a OMPI e o GATT, mas, posteriormente, entenderam que deveriam escolher entre o GATT e o USTR. E elas preferiram um fórum multilateral: o GATT".

Esse distanciamento gradativo das propostas dos países em desenvolvimento possibilitou diferentes resultados após o Acordo de TRIPS. Enquanto países em desenvolvimento, como a Índia, preferiam aceitar as regras de TRIPS, comprometendo-se a adequar suas legislações ao acordo até 2005, o Brasil adotou uma legislação de patentes antes mesmo do término da Rodada Uruguai (Serra, 2001).

A crise econômica dos anos 1980 também dificultou a apresentação de uma proposta mais sólida por parte dos países em desenvolvimento. Como apontam Lima e Hirst (1997:45), tal crise modificou “[...] sensivelmente o contexto internacional que, na década anterior, havia sido mais permissivo para os países industrializados da periferia capitalista".

Para essas autoras, "dois fatores inter-relacionados contribuíram para a deterioração dessas condições: a crise da dívida do Terceiro Mundo e o 'endurecimento' do contexto negociador de questões econômicas entre o Norte e o Sul" (ibidem). Ainda para as autoras, a crise interna dos Estados devedores tornou as nações em desenvolvimento mais vulneráveis às pressões dos países industrializados, dificultando uma possível ação coletiva dentro dos principais regimes econômicos internacionais. Um exemplo dessa desmobilização foi a incorporação do grupo de TRIPS pelo GATT/OMC, apesar da oposição inicial de países em desenvolvimento, como a Índia e o Brasil.

No plano bilateral, o USTR pressionava países com grandes e médios mercados consumidores que possuíssem legislações de propriedade intelectual consideradas flexíveis. Nesse grupo de países, encontravam-se nações asiáticas, como a Índia e a China, e alguns Estados latino-americanos, como o Brasil, o México e a Argentina. A 
Regimes Internacionais e o Contencioso das Patentes para Medicamentos...

pressão do USTR voltava-se especialmente para esses países, porque as elites políticas e empresariais dos Estados Unidos temiam que nações com mercados significativos e com legislações flexíveis pudessem ser um empecilho para a penetração e a concorrência dos produtos norte-americanos.

Os estudos de regimes internacionais não explicam totalmente o pedido feito pela Pharmaceutical Manufacturers Association (PMA), atualmente Pharmaceutical Research and Manufacturers of América para que o USTR utilizasse a seção 301 contra o Brasil. A pressão bilateral norte-americana visava a criação de um regime internacional para a proteção da propriedade intelectual, mas também desejava satisfazer a PMA, que tinha interesses econômicos mais específicos e pertencentes a áreas de "não-regimes". Porém, o posicionamento da PMA também se afinava com a estratégia mais ampla do governo norte-americano para a criação de regimes internacionais (PMA, 1993).

Segundo Tachinardi (1993), mais do que um alvo entre outros, o Brasil era visto como uma espécie de líder dos países em desenvolvimento e possuía um mercado consumidor significativo para os produtos norte-americanos. Para a autora, o conflito entre Brasil e Estados Unidos

“[...] explica-se pelo fato de, em 1988, o país ter ocupado o sétimo lugar no ranking farmacêutico mundial. Era um mercado, obviamente, com uma importância muito grande para os investidores norte-americanos no setor. Sendo assim, poderia ser mau exemplo para os demais países que não protegiam as patentes farmacêuticas" (idem:112).

Conseqüentemente, o tratamento dispensado pelos Estados Unidos com relação ao Brasil deveria ser ainda mais duro do que com os demais países.

Uma das maiores provas do empenho norte-americano em tornar o Brasil um exemplo ocorreu durante o conflito em torno das patentes 
farmacêuticas na década de 1980. O contencioso iniciou-se em decorrência da pressão norte-americana para a alteração do antigo Código de Propriedade Industrial brasileiro (Lei $\mathrm{n}^{\circ}$ 5772, de 21 de dezembro de 1971). A lei de patentes nacional estava adequada à Convenção da União de Paris, de 1883, que dava aos países signatários (entre eles, os Estados Unidos) a liberdade para a proteção de certos produtos e processos de patenteamento. $\mathrm{O}$ antigo código entrava em choque com a estratégia norte-americana de endurecimento dos "princípios, normas, regras e procedimentos de tomada de decisão" relacionados à proteção da propriedade intelectual. Para atingir seus objetivos, em 1988, os Estados Unidos chegaram a aplicar sanções unilaterais contra o Brasil, o que confirma uma idéia presente no projeto "Reestruturação Econômica Mundial e Reformas Liberalizantes nos Países em Desenvolvimento", coordenado pelo professor Sebastião C. Velasco e Cruz, quando se afirma que os Estados Unidos passaram a ameaçar e a retaliar antigos parceiros comerciais, embora estes países não estivessem infringindo nenhuma norma internacional (Velasco e Cruz, 1999:29).

No início da década de 1990, as pressões externas e o conseqüente medo da queda do seu prestígio internacional por ser um país associado à "pirataria" provocaram uma mudança na posição do governo brasileiro em relação à lei de patentes. Essa mudança estimulou o debate em torno da reforma do Código de Propriedade Industrial, cuja nova versão aprovada em 1996 inclui todos os termos aprovados pela Rodada Uruguai do GATT/OMC. Conforme Spector (2003:58), “[...] enquanto o acordo inicial é conduzido no âmbito internacional, a maior parte da implementação deve ser negociada no cenário doméstico, envolvendo atores e interesses que não foram previamente representados". Dessa forma, o processo de adoção do novo código de patentes contraria o percurso usual das negociações para a criação e manutenção de regimes internacionais, pois a discussão interna sobre a "implementação" das regras que seriam acordadas pelo grupo de TRIPS começou antes da finalização da Rodada Uruguai. 
Regimes Internacionais e o Contencioso das

Patentes para Medicamentos...

“[...] o projeto que dá início ao processo de reforma da legislação brasileira sobre propriedade intelectual (o PL 824/91) foi enviado ao Congresso por Collor em 30 de abril de 1991, mais de dois anos, portanto, antes da conclusão da Rodada Uruguai do GATT. Ademais, a lei sancionada em 1996 contém dispositivos que vão além do que está disposto no Acordo celebrado naquela ocasião, como a possibilidade de estender a proteção a produtos ainda em fase de desenvolvimento, o 'pipeline' [...]. Finalmente, o Brasil abriu mão do prazo de que dispunha, segundo o GATT, para adequar sua legislação aos termos do TRIPS - como país 'em desenvolvimento' o Brasil teria até o ano de 2005 para assegurar em lei patente para produtos e processos até então não protegidos [...]" (Velasco e Cruz, 2003:11).

Além das pressões norte-americanas, a eleição de Collor de Mello também contribuiu para que o Brasil enviasse ao Congresso Nacional um Código de Propriedade Intelectual que atendesse às regras do TRIPS antes mesmo da conclusão da Rodada Uruguai do GATT ${ }^{17}$. Esta afirmação não contraria a percepção de que, no final do governo Sarney, foram-se desenhando reformas de cunho liberal (Vigevani e Oliveira, 2004). Apesar de o governo Sarney negociar patentes para processos farmacêuticos, a exigência norte-americana de uma rápida adoção de patentes para produtos levou à retaliação norte-americana em 1988, dificultando a cooperação entre os dois países.

O caso brasileiro encaixa-se perfeitamente nas teses sobre socialização. Conforme Ikenberry e Kupchan (1990:289-290), “[...] a socialização é um processo por meio do qual os líderes nacionais internalizam normas e orientações normativas defendidas pelo hegemon ${ }^{18}$ [...]". Tal processo pode ser provocado pela persuasão ou pela coerção.

Na socialização por meio da persuasão normativa, o Estado mais forte é capaz de assegurar a obediência dos Estados secundários sem recorrer a sanções materiais e induções. Este Estado confia na persuasão ideológica e no aprendizado transnacional por intermédio de várias formas de contato direto com as elites desses Estados, incluindo contato via canais diplomáticos, trocas culturais e intercâmbio de es- 
tudantes. Nessa fórmula, a socialização ocorre independentemente e antes das mudanças na política: esse é o caso de "sanções antes de atos". O consentimento segue-se a partir de mudanças e normas sustentadas pelas elites nos Estados secundários. A cadeia causal é a seguinte: persuasão normativa —-> mudança normativa - > alteração da política (cooperação por meio de dominação legítima) (idem:290).

Na socialização por meio da indução externa, uma grande potência inicialmente utiliza incentivos econômicos e militares para induzir Estados mais fracos a alterarem suas políticas. Essa manipulação das preferências das elites assegura a obediência por meio da coerção. Assim, as elites dos Estados secundários ajustam suas políticas aos princípios defendidos pelo hegemon. Esse é um caso de "atos antes de crenças". Conforme Ikenberry e Kupchan (idem:290-291), a cadeia causal é: indução externa —— mudança política ——> alteração normativa (cooperação por meio de dominação legítima).

A partir da eleição de Collor de Mello, e também durante o governo Fernando Henrique Cardoso, houve uma maior aceitação de políticas de teor liberal como alternativa ao modelo de substituição de importações, reduzindo, com relação ao governo Sarney, a resistência às reformas nas leis de patentes.

Uma análise realista "tradicional" interpretaria a alteração da posição brasileira diante de novas regras internacionais e domésticas como uma resposta à coerção norte-americana realizada por meio da seção 301. Contudo, o Brasil também tinha condições de manter suas políticas, pois o tamanho de sua economia, voltada principalmente para o mercado interno, não permitia que o país fosse totalmente vulnerável às retaliações dos Estados Unidos.

Pode-se argumentar também que uma maior aceitação de políticas de cunho liberal foi mais importante do que as pressões externas para a alteração da posição brasileira na questão das patentes (Lyrio, 1994; 
Regimes Internacionais e o Contencioso das

Patentes para Medicamentos...

Hermann, 2004). Utilizando uma interpretação cognitivista, eu poderia sugerir que "as mudanças no contexto político e no ambiente normativo [...] aconteceram antes das mudanças no ambiente material" (Adler, 1999:231). Mais especificamente, o Brasil alterou suas leis de propriedade intelectual porque já existia em alguns setores da elite brasileira a crença de que esse era o rumo correto a ser tomado.

Como apontam Ikenberry e Kupchan (1990), o papel da socialização interestatal dificilmente pode ser provado empiricamente. O processo de discernir e medir mudanças nas crenças substantivas fica difícil quando lidamos com indivíduos isolados, e mais problemático ainda quando refletimos sobre comunidades de elites com interesses e ideologias difusas. A orientação normativa de uma elite governante freqüentemente não é articulada de forma clara, e, mesmo que seja possível mostrar as mudanças normativas ao longo do tempo, é difícil determinar qual mecanismo está funcionando. Para fazer isto, é preciso uma leitura nuançada da história, além de esforços para inferir crenças a partir de comportamentos (idem:294).

Na questão das patentes, pode-se facilmente argumentar que a retaliação norte-americana em 1988 provocou uma maior aceitação interna das normas e das regras articuladas pelos Estados Unidos. Por outro lado, mudanças na política doméstica brasileira podem ter trazido ao poder uma elite que acreditava na visão econômica "neoliberal" de que a proteção mais rígida da propriedade intelectual traria benefícios para o desenvolvimento do país, pois permitiria uma maior quantia de investimentos internacionais para a pesquisa e o desenvolvimento (P\&D) (Sherwood, 1992; Lyrio, 1994; Hermann, 2004).

No contencioso das patentes, muitas vezes os elementos normativos e materiais por trás das políticas externas dos Estados e das ações dos indivíduos estão tão imbricados que são difíceis de serem separados. Ou seja, a coerção e a persuasão funcionam ao mesmo tempo como forma de convencimento. Contudo, acredito que as ameaças e san- 
ções norte-americanas aceleraram a alteração da política externa brasileira e foram fundamentais para o debate em torno da reforma da antiga lei de patentes nacional.

Segundo Lafer (1998b:45), ministro das Relações Exteriores dos governos de Collor de Mello e de Fernando Henrique Cardoso:

"[...] a condição de possibilidade de acesso aos benefícios do avassalador processo de globalização passa pelo soft power da confiabilidade e da consistência, nos planos interno e internacional, das políticas públicas do Brasil e de seu grau de compatibilidade com o que ocorre no mundo".

Ainda, conforme Lafer (1998a:937), em pronunciamento como representante brasileiro na OMC:

"No Brasil, esse processo ficou mais evidente por causa da crise dos anos 80, a qual revelou o enfraquecimento do modelo de substituição das importações e levou, nos anos 90, a uma reformulação da agenda nacional no sentido da liberalização comercial".

Sem dúvida, a adoção de um novo Código de Propriedade Industrial foi motivada pelas pressões norte-americanas e pela "[...] evolução de cunho acentuadamente liberal que a globalização introduzia, simbolicamente representada pelo caráter das negociações na Rodada Uruguai do GATT [...]" (Vigevani e Oliveira, 2004:5), o que não significa que o Brasil tenha perdido totalmente sua autonomia (margem de manobra) na questão das patentes farmacêuticas, pois, apesar das pressões externas, o código brasileiro ainda permite o fornecimento de licenças compulsórias para a produção local de medicamentos, por meio dos artigos 68 e 71 . O artigo 68 afirma que "o titular ficará sujeito a ter a patente licenciada compulsoriamente se exercer os direitos dela decorrentes de forma abusiva, ou por meio dela praticar abuso de poder econômico [...]". Já o artigo 71 determina que "nos casos de emergência nacional ou interesse público [...] poderá ser concedida [...] licença compulsória, temporária e não exclusiva, para a exploração da patente, sem prejuízo dos direitos do respectivo titular" (Presidência da República, 1996). 
Regimes Internacionais e o Contencioso das Patentes para Medicamentos...

A possibilidade de fornecimento de licenças compulsórias só começou a chamar a atenção dos norte-americanos após a criação do programa brasileiro de combate ao HIV/AIDS. Em 1997, o Brasil tornou obrigatória a distribuição de medicamentos anti-retrovirais aos portadores dessa doença. Para escapar ao monopólio de patentes e diminuir o custo do programa, o Ministério da Saúde, por intermédio da Rede de Laboratórios Farmacêuticos Oficiais, passou a produzir substitutos genéricos desses medicamentos, sendo de fundamental importância a Lei dos Genéricos (Lei no 9.787, de 10 de fevereiro de 1999) para a produção local dessas drogas. A possibilidade de fornecimento de licenças compulsórias para medicamentos genéricos contra o HIV/AIDS chamou a atenção do governo norte-americano, que voltou a pressionar o Brasil ${ }^{19}$.

Como ressaltou José Serra, ministro da Saúde na época, os medicamentos genéricos anti-retrovirais produzidos localmente não afrontavam as regras do TRIPS, uma vez que todos foram desenvolvidos antes de 1997 - quando o Código de Propriedade Industrial (Lei 5.772/71) não permitia o patenteamento de medicamentos (Serra, 2001).

Apesar de o governo brasileiro não chegar a fornecer licenças compulsórias para medicamentos, os Estados Unidos pediram a abertura de um painel no Órgão de Solução de Controvérsias (OSC) da OMC, em 9 de janeiro de 2001, acusando o artigo 68 do Código de Propriedade Industrial de violar as regras do grupo de TRIPS.

Em 18 de maio, graças a uma proposta brasileira, a Assembléia Mundial de Saúde da OMS declarou que o acesso a medicamentos para pacientes com AIDS era um direito humano fundamental. A declaração teve resistência inicial da delegação dos Estados Unidos, que contestava a política brasileira na OMC. Contudo, a proposta foi aprovada com unanimidade pelos 188 membros da OMS por causa 
da pressão da maioria dos Estados signatários dessa instituição (SBPC, 2001; WHO, 2001).

Em junho de 2001, foi feito um acordo out-of-court, no qual os Estados Unidos retiraram a queixa do Órgão de Solução de Controvérsias da OMC e o Brasil se comprometeu a avisar caso resolvesse fornecer licenças compulsórias para medicamentos com patentes de empresas norte-americanas. Segundo Shaffer (2004:28-29), os Estados Unidos retrocederam em suas ameaças contra o Brasil por causa de pressões domésticas realizadas por ONGs e grupos de defesa de direitos humanos e de portadores do HIV/AIDS:

"Em junho de 2001, a administração Bush retirou a queixa dos Estados Unidos contra as provisões brasileiras sobre o licenciamento compulsório contidas na lei de patentes do Brasil após um amplo protesto contra as ações dos Estados Unidos por parte de grupos de ativistas que argumentavam que o governo dos Estados Unidos estava colocando os interesses corporativos acima das preocupações com a vida de seres humanos. $\mathrm{O}$ apoio de organizações de direitos humanos e de saúde internacional complementou as pressões das ONGs".

O resultado do confronto entre Brasil e Estados Unidos é uma evidência de que os países em desenvolvimento podem obter mais ganhos no plano multilateral do que negociando bilateralmente, pois os Estados criam regimes internacionais para antecipar "padrões de comportamento" (reduzir a incerteza) e obter benefícios mútuos em um sistema internacional "interdependente" (Keohane, 1983; 2000).

O respeito às normas e às regras internacionais seria outra razão para os Estados Unidos retirarem a queixa contra o Brasil. Durante as negociações iniciadas na OMC, o corpo diplomático do Ministério das Relações Exteriores (MRE) constatou que os Estados Unidos também possuíam leis que permitiam o licenciamento compulsório, como as apresentadas no título 35, seções 204 e 209, e no título 28, seção 1.498, do United States Code. Dessa maneira, se o Estados Unidos continuassem com o painel, o Brasil possivelmente faria uma 
Regimes Internacionais e o Contencioso das Patentes para Medicamentos...

reclamação formal ao OSC contra a lei norte-americana. Como observado anteriormente, os Estados Unidos foram um dos principais "arquitetos" do TRIPS/OMC e uma perda "relativa" seria mais vantajosa do que prejudicar o regime que eles próprios ajudaram a construir. Contudo, a vitória brasileira não foi incondicional, podendo-se argumentar que o Brasil abriu mão de sua soberania "interna" ao estabelecer um acordo em que se comprometeu a avisar aos Estados Unidos todas as vezes que utilizar o artigo 68 da legislação de patentes nacional:

"[...] o governo dos Estados Unidos retirará o painel contra o Brasil na OMC e o governo brasileiro concordará, quando for necessário utilizar o artigo 68 para o fornecimento de licenças compulsórias para patentes de propriedade de companhias norte-americanas, em avisar antecipadamente os Estados Unidos" (Brazil - United States, 2001).

A IV Conferência Ministerial de Doha, realizada em novembro de 2001, colaborou ainda mais para o enfraquecimento da posição norte-americana. Anteriormente, a III Conferência Ministerial de Seattle, em novembro de 1999, já havia sido considerada um "fiasco" (Thorstensen, 2000; Amorim, 2000a; 2000b; Lamy, 2000). Além disso, as ameaças bioterroristas, após 11 de setembro de 2001, provocaram uma alteração na política externa norte-americana. Como reação a algumas dezenas de atentados utilizando o vírus antraz, o United States Department of Health and Human Services anunciou que forneceria licenças compulsórias para a produção genérica do ciprofloxacin, da Bayer, se a companhia não reduzisse o preço do medicamento, o que enfraqueceu a resistência dos Estados Unidos com relação ao licenciamento compulsório.

Expectativas foram geradas em torno da IV Conferência de Doha, em que foi elaborada a "Declaração sobre o Acordo de TRIPS e Saúde Pública". Esta declaração, reiterando o seu "compromisso com o Acordo de TRIPS", afirma que "cada membro tem o direito de con- 
ceder licenças compulsórias e liberdade para estabelecer os fundamentos para a concessão de tais licenças" (OMC, 2001).

Conforme Abbott (2002), a Declaração de Doha pode ser considerada um acordo, pois os países-membros da OMC declararam consensualmente que concordavam com ela - no texto desse documento, a palavra "concordamos" é utilizada (OMC, 2001). Para o autor, a linguagem jurídica da declaração pode ser interpretada como uma decisão de todos os membros, conforme o artigo 9 do acordo constitutivo da OMC. Prosseguindo com sua argumentação, Abbott (2002) escreve que uma decisão dos membros da OMC também constitui um acordo segundo o artigo 31 da Convenção de Viena sobre os Tratados, o que é equivalente a uma interpretação do Acordo de TRIPS.

Politicamente, a declaração da IV Conferência de Doha indica que o Brasil tem mais possibilidade de obtenção de ganhos em regimes internacionais do que se negociasse bilateralmente com os Estados Unidos, pois "o unilateralismo da política de poder maquiavélico-hobbesiana" é diluído, em parte, pelas regras acordadas entre os Estados-membros dessas instituições (Lafer, 1998b:28). Contudo, segundo aponta Lanoszka (2003:182),

"O Acordo de TRIPS considera-se limitado a padrões mínimos de proteção da Propriedade Intelectual [...]. Esses padrões, entretanto, são modelados por práticas legais do Ocidente e são organizados em um nível compatível àquelas dos países desenvolvidos".

Além disso, existe um movimento de adoção de práticas legais baseadas em modelos norte-americanos e europeus. Kelemen e Sibbitt (2004) argumentam que o direito norte-americano se está espalhando para outras jurisdições (eles estudaram o Japão e a União Européia), pois a liberalização econômica força os governos de outros países a adotarem regras mais flexíveis, próximas às praticadas nos Estados Unidos. Shaffer (2004:15) mostra que os Estados Unidos e os países da União Européia utilizam mais o OSC da OMC. Conse- 
Regimes Internacionais e o Contencioso das

Patentes para Medicamentos...

qüientemente, os governos que participam mais ativamente do sistema de solução de controvérsias da OMC têm maiores possibilidades de moldar a interpretação do Acordo de TRIPS/OMC por causa da importância dada à jurisprudência nesse regime internacional.

\section{Considerações Finais}

Os países em desenvolvimento, como o Brasil, têm mais possibilidade de obter ganhos em regimes internacionais do que em negociações bilaterais com poderosos países desenvolvidos. Geralmente, o poder é mais diluído nas instituições internacionais, pois mesmo os Estados fortes podem mais facilmente ser objeto da ação coletiva realizada pelas nações mais fracas. Na Declaração de Doha, em novembro de 2001, alguns países em desenvolvimento (especialmente Brasil, Índia e África do Sul) estabeleceram alianças com ONGs de direitos humanos e de AIDS (Médicos sem Fronteiras, The Oxford Committee for Famine Relief (Oxfam), Consumer Project on Technology (CPT) etc.), criando uma coalizão eficiente nas negociações.

Segundo Drahos (2003:4), nenhuma vitória semelhante havia sido alcançada pelos países em desenvolvimento envolvidos em disputas bilaterais com os Estados Unidos ou com a União Européia. No entanto, apesar de existirem indícios de que a OMC oferece melhores perspectivas para os países mais fracos do que as negociações bilaterais, os regimes não são fóruns necessariamente favoráveis às nações em desenvolvimento.

As instituições internacionais nem sempre neutralizam as desigualdades de poder entre os países, pois, entre outros fatores, uma negociação multilateral também oferece oportunidades para os Estados fortes formarem coalizões, assim como fazem com os países fracos. Durante a Rodada Uruguai, por exemplo, os níveis de cooperação entre os Estados Unidos e a Comunidade Européia foram bastante altos. 
A negociação comercial multilateral também não diminui a capacidade de os Estados fortes fazerem ameaças críveis. Estas ameaças podem ser consideráveis em contextos multilaterais porque os Estados fracos, após obterem certas concessões, podem ficar "desesperados" para que as negociações terminem e, conseqüentemente, "psicologicamente" mais expostos às demandas dos mais fortes.

Uma negociação comercial multilateral também pode "forçar" a realização de cálculos complexos sobre uma gama de matérias por parte dos Estados fracos. Portanto, tais países em desenvolvimento passam a gastar mais energia em recursos analíticos do que em uma negociação bilateral limitada a uma única questão, como, por exemplo, propriedade intelectual ou investimentos.

A partir da experiência dos países em desenvolvimento na Rodada Doha, este artigo sugere que nações pouco poderosas, como o Brasil, deveriam buscar alianças mais duradouras para aumentar suas capacidades de negociação. Tais coalizões podem ser informais ou institucionalizadas, contando ou não com a participação de atores "transnacionais" (como ONGs de direitos humanos e AIDS ou empresas farmacêuticas), conforme o contexto em que as negociações ocorram.

De acordo com Drahos (idem:6), existem quatro fontes básicas para determinar o poder de barganha de um país: o tamanho dos mercados internos, a criação de rede de inteligência, a capacidade de criar alianças e a eficiência das instituições democráticas domésticas.

O controle sobre um amplo mercado doméstico é uma poderosa "carta" nas negociações comerciais. Um país que pode oferecer acesso ao seu grande mercado, criando relações de interdependência assimétricas favoráveis, está em posição de fazer ameaças críveis. Nessa direção, a utilização do Sistema Geral de Preferências (SGP) dos Estados Unidos é um exemplo de como um país pode usar o seu mercado interno para obter vantagens nas negociações internacionais ${ }^{20}$. 
Regimes Internacionais e o Contencioso das

Patentes para Medicamentos...

Em segundo lugar, as chamadas "redes de inteligência" são uma importante fonte do poder de barganha. Elas armazenam, distribuem e analisam informações relacionadas ao comércio, à economia e aos negócios internacionais. Fazem parte dessas redes a burocracia estatal, suas organizações de negócios (por exemplo, câmaras de comércio), assim como empresas e ONGs.

Em terceiro lugar, a capacidade de o Estado abarcar outros atores, tanto estatais quanto não estatais, criando uma coalizão que gira em torno de interesses e de demandas em comum é uma outra fonte importante do poder de barganha. As empresas multinacionais sempre receberam atenção dos estudiosos de negociações comerciais, porém, as ONGs de direitos humanos e de AIDS tiveram um papel bastante significativo na "vitória" dos países em desenvolvimento em Doha. Nesse sentido, o crescimento da importância das ONGs pode ser um fenômeno passageiro ou uma tendência que os estudiosos de relações internacionais devem acompanhar de perto.

Finalmente, uma quarta fonte de poder de barganha reside no bom funcionamento das instituições democráticas. As regras de tomada de decisão doméstica e de delegação da autoridade negociadora afetam a capacidade de barganha estatal. Como Putnam (1993) salientou, uma nação que dá pouca autonomia para seus líderes pode aumentar o poder de barganha estatal, pois dá aos negociadores internacionais o argumento de que eles não podem agir sem o consentimento da opinião pública ou de formuladores de decisões nacionais. Por outro lado, como o estudo de caso proposto exemplifica, a falta de coesão doméstica norte-americana foi um elemento de fraqueza nas negociações internacionais daquele país.

As negociações de Doha foram um exemplo da efetividade de uma aliança informal e complexa, composta por países em desenvolvimento e ONGs de direitos humanos e de AIDS. Contudo, Doha também sugere alguns limites para a atuação de alianças informais. A 
"Campanha de Acesso a Medicamentos" ocorreu, em grande parte, por causa da crise na manutenção dos programas de tratamento de AIDS nas nações em desenvolvimento; estes países não moldaram as agendas das negociações internacionais, apenas reagiram eficazmente a medidas que contrariavam seus interesses. Além disso, como as coalizões não foram institucionalizadas, não existe garantia de que elas permanecerão intactas caso as mesmas questões voltem a ser debatidas futuramente.

As vitórias do Brasil no contencioso com os Estados Unidos foram possíveis graças a uma conjunção de fatores que aumentaram a capacidade de negociação brasileira. Especificamente, o apoio de alguns atores "transnacionais", as disputas nos regimes internacionais e a falta de coesão doméstica norte-americana ajudaram o governo brasileiro a defender suas posições. Por outro lado, não existe nenhuma garantia de que as nações mais fracas sempre obterão ganhos se procurarem resolver seus conflitos em regimes internacionais, buscarem apoios de outros atores "transnacionais", assim como de outros países com interesses semelhantes. Existem diversos fatores que podem indeterminar os ganhos dos países em desenvolvimento. Talvez o elemento mais forte do poder de barganha dos países desenvolvidos seja a capacidade de utilizarem seus mercados internos, oferecendo vantagens para que certas nações em desenvolvimento não tenham incentivos para estabelecer coalizões duradouras. Contudo, por terem pouca margem para agir unilateralmente, estas nações devem procurar apoio no cenário internacional e tentar descobrir as possíveis fraquezas de seus adversários, mesmo que essas sejam tarefas difíceis.

Qualquer oportunidade que um país em desenvolvimento tenha de aumentar a sua capacidade de negociação deve ser levada em consideração. Por esse motivo, sugiro que mais trabalhos empíricos sejam realizados para tornar claro se as considerações feitas aqui realmente podem ajudar a explicar outras disputas entre países em desenvolvi- 
Regimes Internacionais e o Contencioso das Patentes para Medicamentos...

mento com nações mais poderosas. Pesquisas "normativas" que sugiram melhorias no aparato burocrático brasileiro para aprofundar o diálogo entre o governo e a sociedade civil, e o aperfeiçoamento das estratégias de negociações nacionais também são importantes. Nesse sentido, o aperfeiçoamento das nossas instituições democráticas, a ampliação de pesquisas (universitárias e extra-acadêmicas) sobre comércio internacional e estratégias bem elaboradas para a formação de coalizões com países que possuam interesses semelhantes colaborarão para melhorarmos nossa capacidade de negociação no cenário internacional.

\section{Notas}

1. Marx, Weber e Durkheim são autores exemplares entre os chamados "analistas sociais clássicos" (Rosenberg, 1994; Mills, 1969).

2. Utilizo as palavras "instituições" e "regimes internacionais" como sinônimos (Ruggie, 1983; 1998; Young, 1983; Mearsheimer, 2000).

3. "Perspectiva" e "abordagem" são sinônimos. Contudo, não correspondem ao termo "filosofia", pois não apresentam a mesma sistematização geralmente associada a este.

4. Krasner (1983a) e Hasenclever et alii (1997) elaboraram uma classificação simples, enquanto outros autores, como Haas (1983), separam as escolas de uma forma mais complexa, que, a meu ver, atrapalha o entendimento das diferenças essenciais entre elas. Haas examina seis "teorias" de regimes: o ecoambientalismo, o ecorreformismo, o igualitarismo, o liberalismo, o mercantilismo e o mainstream.

5. Existe uma ampla discussão a respeito da centralidade ou não dos Estados Nacionais. Partimos do pressuposto de que os Estados são atores centrais. Evans (1997), Waltz (1979), Keohane e Nye (1989) acreditam na centralidade dos Estados, enquanto Archibugi et alii (1998) e Held e Mcgrew (2001) dizem que os Estados Nacionais estão perdendo importância.

6. Especula-se que algumas armas expostas nas paradas militares da ex-URSS tinham finalidade de mostrar um poderio bélico acima do existente. Nesse senti- 
Gabriel Cepaluni

do, muitos armamentos não passavam de maquetes de papelão com fins propagandísticos. Essa estratégia de marketing servia para mostrar aos Estados Unidos que aquele país tinha mais recursos do que na realidade possuía.

7. A expressão "retaliação" vem do latim e, em sua origem, significava aplicar a pena de Talião, isto é, castigar com mal ou pena igual à ofensa recebida. A palavra "sanção" refere-se à aplicação da pena jurídica para a hipótese de violação de um preceito. Do ponto de vista brasileiro, as medidas unilaterais norte-americanas são interpretadas como uma "sanção", enquanto os Estados Unidos dizem estar "retaliando" o Brasil por desrespeito às propriedades intelectuais das empresas daquele país. Aqui, utilizo as duas expressões como sinônimos.

8. Chamar um "teórico" de grociano implica que ele seja fundamentalmente influenciado por Hugo Grotius. Porém, nenhum autor do livro International Regimes faz referência a esse autor, a não ser o próprio organizador da obra (Krasner, 1983a; 1983b).

9. O ótimo de Pareto é qualquer situação em que o bem-estar de pelo menos um dos participantes pode aumentar sem trazer prejuízo aos demais.

10. A anarquia é entendida como ausência de poder central ou de governo mundial, não como falta de ordem ou sinônimo de caos.

11. Hasenclever et alii (1997) utilizam a palavra "teoria" indiscriminadamente. Eles confundem a noção de perspectiva ou abordagem com a idéia de teoria. Assim, utilizo as palavras "perspectiva" ou "abordagem", enquanto esses autores preferem usar o termo "teoria". Nota-se, contudo, que a noção de teoria pressupõe uma maior sistematização que o conceito de "abordagem".

12. Conforme Hasenclever et alii (1997), Peter Haas, Oran Young e Emanuel Adler seriam exemplos de cognitivistas "fracos", enquanto Thomas Franck, Friedrich Kratochwil, Herald Müller, John Gerard Ruggie e Robert Cox são considerados cognitivistas "fortes".

13. A robustez do regime (resiliência) refere-se à capacidade de uma instituição continuar existindo mesmo após alterações no poder internacional ou no caso de os participantes mais fortes descobrirem que seus interesses não estão sendo mais servidos adequadamente (Hasenclever et alii, 1997:2).

14. "O número e as atividades das ONGs que operam nas relações estrangeiras aumentaram dramaticamente desde a Segunda Guerra Mundial de menos de 3 mil em 1945 para mais de 13 mil em 1990" (Haufler, 1993).

15. Putnam (1993:434) acreditava que as relações entre as políticas externas e internas deixaram de ser um aspecto importante nos trabalhos de Keohane e 
Regimes Internacionais e o Contencioso das

Patentes para Medicamentos...

Nye, especialmente quando "[...] o conceito de regime internacional veio dominar este campo de estudo". No entanto, alguns autores buscaram estabelecer conexões entre o conceito de regime e a influência dos fatores domésticos na formulação da política externa (Hurrell, 1993; Goldstein, 1998; Cortell e Davis Jr., 2000; Spector, 2003).

16. O G-10 era composto pela Argentina, Cuba, Egito, Índia, Nicarágua, Nigéria, Peru, Tanzânia, Iugoslávia e Brasil.

17. A aceitação das normas e dos princípios acordados em regimes internacionais ocasiona uma redução da soberania "doméstica" dos países-membros (Krasner, 1983a; Puchala e Hopkins, 1983). Conforme Bull (2002:13), a soberania "interna" é "a supremacia sobre todas as demais autoridades dentro daquele território e com respeito a essa população". Com a criação de regimes, os países submetem-se a normas, princípios e regras internacionais e, em decorrência, sofrem influências externas em seus "negócios domésticos" ("domestic" affairs).

18. Neste caso, hegemon tem o mesmo significado de líder. O termo "hegemonia" vem do grego e refere-se à noção de "comando" e "liderança".

19. Em 22 de agosto de 2001, após seis meses de negociação, o Brasil ameaçou fornecer licenças compulsórias para o medicamento nelfinavir, fabricado pela empresa suíça Roche, caso o laboratório não reduzisse o preço desse remédio (Brazilian Ministry of Health, 2001). Em 31 de agosto do mesmo ano, as duas partes chegaram a um acordo: a Roche abaixou o preço do medicamento em 40\% e o Brasil não forneceu licenças compulsórias (Roche, 2001).

20. Os países em desenvolvimento que estão no Sistema Geral de Preferências (SGP) dos Estados Unidos recebem concessões comerciais não recíprocas. 


\title{
Referências Bibliográficas
}

\begin{abstract}
ABBOTT, Frederick M. (2002), "The Doha Declaration on the TRIPS Agreement and Public Health: Lighting a Dark Corner at the WTO”. Journal of International Economic Law, vol. 5, nº 2.
\end{abstract}

ABREU, Marcelo de Paiva. (2001), “O Brasil, o GATT e a OMC: História e Perspectivas”. Política Externa, vol. 9, nº 4.

ADLER, Emanuel. (1999), “O Construtivismo no Estudo das Relações Internacionais". Lua Nova, nº 47.

AMORIM, Celso. (2000a), “A OMC e o Ano 2000”. Carta Internacional, ano VIII, $n^{\circ} 85$.

(2000b), “A OMC pós-Seattle”. Política Externa, vol. 8, n 4.

ARCHIBUGI, Daniele et alii (eds.). (1998), Re-imagining Political Community, Studies in Cosmopolitan Democracy. Cambridge, Polity Press.

ARON, Raymond. (1979), Paz e Guerra entre as Nações. Brasília, Editora UnB.

(1985), “O que É uma Teoria das Relações Internacionais?” (2 ed.). Estudos Políticos. Brasília, Editora UnB.

ARRIGHI, Giovanni. (1994), O Longo Século XX. São Paulo, Editora Unesp.

ARSLANIAN, Regis Percy. (1994), O Recurso à Seção 301 da Legislação de Comércio Norte-Americana e a Aplicação de seus Dispositivos contra o Brasil. Brasília, Instituto Rio Branco.

e LYRIO, Maurício Carvalho. (1995), “A Reforma da Lei de Patentes no Brasil e as Pressões Norte-Americanas na Área de Propriedade Intelectual”. Política Externa, vol. 4, n 2. Disponível em <http://www.politicaexterna.com. br/artset95.htm>.

AYOOB, Mohammed. (2002), "Inequality and Theorizing in International Relations: The Case for Subaltern Realism". International Studies Review, vol. 4, $\mathrm{n}^{\circ} 3$. 
Regimes Internacionais e o Contencioso das Patentes para Medicamentos...

BASSO, Maristela. (2000), O Direito Internacional da Propriedade Intelectual. Porto Alegre, Livraria do Advogado Editora.

BRAITHWAITE, John. (2004), Methods of Power for Development: Weapons of the Weak, Weapons of the Strong. Paper apresentado durante a Conferência Globalization, Law and Development. University of Michigan Law School.

BRAZIL - UNITED STATES. (25 de junho de 2001), "Joint Communication Brazil - United States". Disponível em <http://www.cptech.org/ip/health/c/ brazil/statement06252001.html>.

BRAZILIAN MINISTRY OF HEALTH. (2001), Ministry of Health Announces Compulsory Licensing of Nelfinavir Patent. Press Release, 22 de agosto. Disponível em <http://www.cptech.org/ip/health/c/brazil/nelf08222001. html>.

BULL, Hedley. (2002), A Sociedade Anárquica. Brasília/São Paulo, Editora UnB/IPRI/IOESP.

CORTELL, Andrew P. e DAVIS JR., James W. (2000), “Understanding the Domestic Impact of International Norms: A Research Agenda". International Studies Review, vol. $2, \mathrm{n}^{\circ} 1$.

COX, Robert W. (1986), "Social Forces, States and World Orders: Beyond International Relations Theory", in R. O. Keohane, Neoliberalism and Its Critics. New York, Columbia University.

DRAHOS, Peter. (2003), "When the Weak Bargain with the Strong: Negotiations in the WTO”. International Negotiation, vol. $8, \mathrm{n}^{\circ} 1$.

DRYDEN, Steve. (1995), Trade Warriors: USTR and the American Crusade for Free Trade. New York, Oxford University Press.

EVANS, Peter. (1990), “O Declínio da Hegemonia e a Industrialização Afirmativa: Conflitos entre Brasil e Estados Unidos na Indústria de Computadores". Dados - Revista de Ciências Sociais, vol. 33, nº 2 .

. (1997), "The Eclipse of the State: Reflexions on Stateness in an Era of Globalization”. World Politics, vol. 50, $\mathrm{n}^{\circ} 1$.

GILPIN, Robert. (2002), A Economia Política das Relações Internacionais. Brasília, Editora UnB.

GOLDSTEIN, Judith. (1998), "International Institutions and Domestic Politics: GATT, WTO, and the Liberalization of International Trade", in A. O. Krue- 


\section{Gabriel Cepaluni}

ger (ed.), The WTO as an International Organization. Chicago/London, The University of Chicago Press.

HAAS, Ernest B. (1983), "Words Can Hurt You: Or, Who Said What to Whom about Regimes", in S. D. Krasner (org.), International Regimes. Ithaca/London, Cornell University Press.

HAAS, Peter M. (1990), Saving the Mediterranean: The Politics of International Environmental Cooperation. New York, Columbia University Press.

HASENCLEVER, Andreas et alii. (1997), Theories of International Regimes. Cambridge, Cambridge University Press.

HAUFLER, Virginia. (1993), “Crossing the Boundary Between Public and Private: International Regimes and Non-State Actors", in V. Rittberger (ed.), Regime Theory and International Relations. Oxford, Clarendon Press.

HELD, David e MCGREW, Anthony. (2001), Prós e Contras da Globalização. Rio de Janeiro, Jorge Zahar Editor.

HERMANN, Breno. (2004), O Brasil e a Lei de Propriedade Industrial (9.279/96): Um Estudo de Caso da Relação Interno-Externo. Dissertação de Mestrado, UnB, Brasília.

HURRELL, Andrew. (1993), "International Society and the Study of Regimes: A Reflective Approach", in V. Rittberger (ed.), Regime Theory and International Relations. Oxford, Clarendon Press.

IKENBERRY, G. John e KUPCHAN, Charles A. (1990), "Socialization and Hegemonic Power". International Organization, vol. 44, nº 3 .

KECK, Margareth E. e SIKKINK, Kathryn. (1998), Ativists Beyond Borders: Advocacy Networks in International Politics. Ithaca/London, Cornell University Press.

(1999), “Transnational Advocacy Networks in International and Regional Politics”. International Social Science Journal, vol. 51, nº 159.

KELEMEN, R. Daniel e SIBBITT, Eric C. (2004), “The Globalization of American Law". International Organization, vol. 58, $\mathrm{n}^{\circ} 1$.

KENNEDY, Paul. (1989a), Ascensão e Queda das Grandes Potências. Rio de Janeiro, Editora Campus. 
Regimes Internacionais e o Contencioso das

Patentes para Medicamentos...

. (1989b), “A América Está Ficando para trás?” (entrevista concedida a Robert Helbroner). Diálogo, vol. 23, n 1 .

KEOHANE, Robert O. (1983), “The Demand for International Regimes”, in S. D. Krasner (org.), International Regimes. Ithaca/London, Cornell University Press.

. (2000), “The Promise of International Institutions”, in M. E. Brown, O. R. Coté Jr., S. M. Lynn-Jones e Steven E. Miller (eds.), Theories of War and Peace. Cambridge/London, The MIT Press.

e NYE, Joseph S. (1989), Power and Interdependence ( $2^{\mathrm{a}}$ ed.). Glenview, Scott, Foresman and Company.

(1998), "Power and Interdependence in the Information Age". Foreign Affairs, vol. 77, $\mathrm{n}^{\circ}$ 55. Disponível em <http://www.ksg.harvard.edu/prg/nye/ power.pdf $>$.

KRASNER, Stephen D. (1983a), "Structural Causes and Regimes Consequences: Regimes as Intervening Variables”, in S. D. Krasner (org.), International Regimes. Ithaca/London, Cornell University Press.

. (1983b), "Regimes and the Limits of Realism: Regimes as Autonomous Variables", in Stephen D. Krasner (org.), International Regimes. Ithaca/London, Cornell University Press.

(2001), "Globalization, Power and Authority". Disponível em $<$ http://pro.harvard.edu/papers/000/000008KrasnerSte.pdf>.

LAFER, Celso. (1998a), "Réflexions sur l'OMC lors du 50e Anniversaire du Système Multilatéral Commercial: L'Impact d'un Monde en Transformation sur le Droit International Économique". Journal du Droit International, 125e année, $n^{\circ} 4$.

(1998b), A OMC e a Regulamentação do Comércio Internacional: Uma Visão Brasileira. Porto Alegre, Livraria do Advogado Editora.

LAMY, Pascal. (2000), "Pos-Seattle: A Vision of Globalization and of the Challenges Ahead". Carta Internacional, nº 85.

LANOSZKA, Anna. (2003), “The Global Politics of Intellectual Property Rights and Pharmaceutical Drug Policies in Developing Countries". International Political Science Review, vol. 24, n 2. 
Gabriel Cepaluni

LIMA, Maria Regina Soares de e HIRST, Mônica. (1997), “O Brasil e os Estados Unidos: Dilemas e Desafios de uma Relação Complexa", in S. H. N. de Cas-

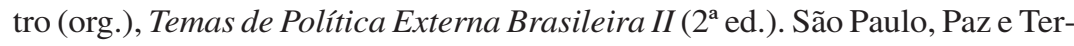
ra, vol. 2 .

LYRIO, Maurício Carvalho. (1994), O Contencioso das Patentes Farmacêuticas e as Relações entre Brasil e Estados Unidos. Dissertação de Mestrado, PUC-Rio, Rio de Janeiro.

MEARSHEIMER, John J. (2000), “The False Promise of International Institutions”, in M. E. Brown, O. R. Coté Jr., S. M. Lynn-Jones e S. E. MILLER (eds.), Theories of War and Peace. Cambridge/London, The MIT Press.

MERTON, Robert King. (1968), "Funções Manifestas e Latentes”, in Sociologia: Teoria e Estrutura. São Paulo, Mestre Jou.

MILLS, Charles Wright. (1969), A Imaginação Sociológica (2 ${ }^{\mathrm{a}}$ ed.). Rio de Janeiro, Zahar Editores.

NYE JR., Joseph S. (1997), Understanding International Conflicts: An Introduction to Theory and History ( $2^{\mathrm{a}} \mathrm{ed}$.). New York, Longman.

(2002), O Paradoxo do Poder Norte-Americano. São Paulo, Editora Unesp.

OMC - Organização Mundial do Comércio. (2001), "Declaração sobre o Acordo TRIPS e Saúde Pública”. Política Externa, vol. 12, nº 3.

PMA - Pharmaceutical Manufacturers Association. (1993) [1987], "Petition for Relief Pursuant to Section 301 of the Trade Act of 1974, as Amended-Denial by the Government of Brazil of Fair and Equitable Provision of Adequate and Effective Protection of Intellectual Property Rights", in M. S. P. B. Frota, Proteção de Patentes de Produtos Farmacêuticos: O Caso Brasileiro. Brasília, IPRI.

PRESIDÊNCIA DA REPÚBLICA. (1996), “Código de Propriedade Industrial: Lei n ${ }^{\circ}$ 9.279, de 14 de maio de 1996”. Disponível em <http://www.planalto. gov.br/ccivil_03/Leis/L9279.htm>.

PUCHALA, Donald J. e HOPKINS, Raymond F. (1983), "International Regimes: Lessons from Indutive Analysis", in S. D. Krasner (org.), International Regimes. Ithaca/London, Cornell University Press. 
Regimes Internacionais e o Contencioso das

Patentes para Medicamentos...

PUTNAM, Robert. (1993), "Diplomacy and Domestic Politics: The Logic of Two-Level Games”, in P. Evans, H. K. Jacobson e R. D. Putnam (eds.), Double-Edged Diplomacy. Berkeley, University of California Press.

ROCHE. (2001), Roche and the Brazilian Ministry of Health Reach Agreement for Supply of HIV Drug Viracept (Nelfinavir). Press Release, 31 de agosto. Disponível em <http://www.globalpolicy.org/socecon/develop/aids/2001/0904 roche.htm>.

ROSENBERG, Justin. (1994), “The International Imagination: IR Theory and Classic Social Analysis”. Millennium: Journal of International Studies, vol. 23, $\mathrm{n}^{\mathrm{o}} 1$.

RUGGIE, John Gerard. (1983), "International Regimes, Transactions, and Change: Embedded Liberalism in the Postwar Economic Order", in S. D. Krasner (org.), International Regimes. Ithaca/London, Cornell University Press.

. (1998), "Embedded Liberalism and the Postwar Economic Regimes", in J. G. Ruggie (org.), Constructing the World Polity: Essays on International Institutionalization. London/New York, Routledge.

SANCHEZ, Michelle Ratton. (2002), “Atores Não-Estatais e sua Relação com a Organização Mundial do Comércio", in A. Amaral Jr. (org.), Direito do Comércio Internacional. São Paulo, Editora Juarez de Oliveira.

. (2004), Demandas por um Novo Arcabouço Sociojurídico na Organização Mundial do Comércio e o Caso do Brasil. Tese de Doutorado, Faculdade de Direito-USP, São Paulo.

SBPC - Sociedade Brasileira para o Progresso da Ciência. (2001), "Medicamentos Anti-AIDS e Quebra de Patentes: O Conflito Diplomático em torno das Patentes", disponível em <http://www.comciencia.br/especial/pataids/ pataids04.htm>, 25 de julho.

SELL, Susan e PRAKASH, Aseem. (2004), "Using Ideas Strategically: The Contest Between Business and NGO Networks in Intellectual Property Rights". International Studies Quartely, vol. 48, $\mathrm{n}^{\circ} 1$.

SERRA, José. (2001), “Patentes, uma Questão Vital para os Brasileiros”. Carta Internacional, $\mathrm{n}^{\mathrm{o}} 102$.

SHAFFER, Gregory. (2004), Recognizing Public Goods in WTO Dispute Settlement: Who Participates? Who Decides? The Case of TRIPS and Pharmaceutical Patent Protection. Wisconsin. Manuscrito. 


\section{Gabriel Cepaluni}

SHERWOOD, Robert M. (1992), Propriedade Intelectual e Desenvolvimento Econômico. São Paulo, Edusp.

SHUKLA, S. P. (2002), "From the GATT to the WTO and Beyond", in D. Nayyar (ed.), Governing Globalization: Issues and Institutions. Oxford, Oxford University Press.

SPECTOR, Bertram I. (2003), "Deconstructing the Negotiations of Regime Dynamics", in B. I. Spector e W. I. Zartman (eds.), Getting it Done: Post-Agreement Negotiations and International Regimes. Washington, D.C., United States Institute of Peace Press.

STRANGE, Susan. (1983), "Cave! Hic Dragones: A Critique of Regime Analysis”, in S. D. Krasner (org.), International Regimes. Ithaca/London, Cornell University Press.

TACHINARDI, Maria Helena. (1993), A Guerra das Patentes: O Conflito Brasil X Estados Unidos sobre Propriedade Intelectual. São Paulo, Paz e Terra.

THORSTENSEN, Vera. (2000), “OMC: A Retomada dos Trabalhos após o Impasse de Seattle”. Política Externa, vol. 9, nº 3.

UNITED STATES. (1974), “Trade Act of 1974”, in J. H. Jachson, W. J. Davey e A. O. Sykes Jr. (2002), Documents Supplement to Legal Problems of International Economic Relations. Minnesota, West Group.

USTR. (2002), "Section 301 Table of Cases". Disponível em $<$ http://www.ustr.gov/html/act301idx.htm>.

VAITSOS, Constantine V. (1989), "Radical Technological Changes and the New 'Order' in the World-Economy". Review, vol. 12, nº 2.

VELASCO e CRUZ, Sebastião C. (1999), Reestruturação Econômica Mundial e Reformas Liberalizantes nos Países em Desenvolvimento. Projeto de Pesquisa, São Paulo, FAPESP.

(2003), Organizações Internacionais e Reformas Neoliberais: Reflexões a partir do Tema da Propriedade Intelectual. Manuscrito.

VIGEVANI, Tullo. (1995), O Contencioso Brasil X Estados Unidos da Informática: Uma Análise sobre Formulação da Política Exterior. São Paulo, Editora Alfa-Omega/Edusp. 
Regimes Internacionais e o Contencioso das Patentes para Medicamentos...

e OLIVEIRA, Marcelo F. de. (2004), A Política Externa Brasileira na Era FHC: Um Exercício de Autonomia pela Integração. São Paulo. Manuscrito.

WALTZ, Kenneth N. (1979), Theory of International Politics. Massachusetts, Addison-Wesley Publishing Company.

(2000), "Structural Realism after the Cold War". International Security, vol. $25, \mathrm{n}^{\mathrm{o}} 1$.

WEBER, Max. (1991), Economia e Sociedade: Fundamentos da Sociologia Compreensiva. Brasília, Editora UnB.

(1999), “A ‘Objetividade’ do Conhecimento nas Ciências Sociais”, in G. Cohn (org.), Max Weber: Sociologia. São Paulo, Ática.

WENDT, Alexander. (1994), "Collective Identity Formation and The International State”. American Political Science Review, vol. 88, nº 2.

. (2004), "The State as Person in International Theory". Review of International Studies, vol. 30.

WHO - World Health Organization. (2001), "Fifth-Four World Health Assembly: Third Report of Committee A", disponível em $<$ http://www.who.int/en/>, 18 de maio.

YOUNG, Oran. (1983), "Regime Dynamics: The Rise and Fall of International Regimes”, in S. D. Krasner (org.), International Regimes. Ithaca/London, Cornell University Press. 


\title{
Resumo
}

\section{Regimes Internacionais e o Contencioso das Patentes para Medicamentos: Estratégias para Países em Desenvolvimento}

\begin{abstract}
Este artigo mostra que não existe apenas uma única teoria sobre regimes internacionais, mas um conjunto de estudos teóricos e empíricos que, isoladamente ou em conjunto, não constituem uma "teoria geral" das relações internacionais. Três abordagens resumem os principais debates sobre os regimes: o realismo-estrutural, o neoliberalismo e o cognitivismo. A primeira perspectiva - a realista - considera que o poder é o principal conceito para explicar os regimes internacionais. O neoliberalismo considera que o interesse é a principal noção analítica para entender a criação e a manutenção dos regimes. Finalmente, o cognitivismo coloca as idéias e os valores no centro de suas explicações. Feitas essas considerações, analisa-se o contencioso das patentes farmacêuticas entre o Brasil e os Estados Unidos (1988-2001) utilizando insights fornecidos pelos estudos de regimes internacionais - privilegiando-se a abordagem neoliberal. A partir do conflito entre o Brasil e os Estados Unidos, também são desenhadas algumas estratégias que podem ser utilizadas pelos países em desenvolvimento para maximizar seus ganhos no cenário internacional.
\end{abstract}

Palavras-chave: Regimes Internacionais - Patentes - Política Externa GATT/OMC

Abstract

\section{International Regimes and the Medical Patent Dispute: Strategies for Developing Countries}

This article demonstrates that there is not one international regime theory, but a set of theoretical and empirical studies that, alone or together, do not constitute a "general theory" of International Relations. Three approaches summarise the main debates on regimes: structural realism, neoliberalism, and cognitivism. The first perspective - the realist - considers power as the 
Regimes Internacionais e o Contencioso das Patentes para Medicamentos...

main concept for explaining international regimes. Neoliberalism considers interest as the main analytical tool to understand the creation and maintenance of regimes. Finally, cognitivism places ideas and values at the center of its explanations. After establishing these perspectives, the pharmaceutical patents dispute between Brazil and the United States (1988-2001) is analyzed, utilizing insights gained by the study of international regimes - privileging the neoliberal approach. From this conflict between Brazil and the United States, some strategies are also outlined that can be used by developing countries to maximize their gains on the international stage.

Key words: International Regimes - Patents - Foreign Affairs GATT/WTO 